\title{
Constituents of Essential Oil from the Dried Fruits and Stems of Akebia quinata (THUNB.) DECNE.
}

\author{
Jyunichi Kawata ${ }^{1}$, Munekazu Kameda ${ }^{2}$ and Mitsuo Miyazawa ${ }^{1 *}$ \\ ${ }^{1}$ Department of Applied Chemistry, Faculty of Science and Engineering, Kinki University (3-4-1, Kowakae, Higashiosaka-shi, Osaka 577- \\ 8502, JAPAN) \\ ${ }^{2}$ More Cosmetics Co., Ltd. (1-6-12 Kyutaromachi, Chuo-ku, Osaka 541-0056, JAPAN)
}

\begin{abstract}
The compositions of the essential oil from AKEBIAE FRUCTUS and AKEBIAE CAULIS, the dried fruits and stems of Akebia quinata (Thunb.) DECNE. (Lardizabalaceae), have been investigated by GC and GC/MS. As a result, the fruits oil was revealed the presence of 86 components, representing $98.4 \%$ of the total oil. The major compounds of the fruits oil were limonene, eugenol, octanal and $p$-cymene. The monoterpenoids and saturated short-chain aldehyde $(\mathrm{C6} \sim \mathrm{C} 10)$ were main volatile fractions of the oil. Ninety components accounting for $90.5 \%$ of constituents of stems oil were identified, and the main compounds of the oil were hexanoic acid, palmitic acid, $(2 E, 4 E)$-decadienal and hexanol. The oil had high content of saturated fatty acids $(\mathrm{C6} \sim \mathrm{C16})$, and unsaturated short-chain aldehyde $(\mathrm{C6} \sim \mathrm{C10})$.
\end{abstract}

Key words: Akebia quinata (ThunB.) DeCNE., AKEBIAE FRUCTUS, AKEBIAE CAULIS, Lardizabalaceae, essential oil

\section{INTRODUCTION}

Lardizabalaceae consist of 7 genes with about 35 species of woody plants, which were found eastern Asia, from the Himalayan to Japan. Most investigatory species of the family, Akebia quinata (Thunb.) Decne. ('akebi' in Japanese) commonly referred to as chocolate vine, grow naturally in Japan and China (Kiangsu, Honan, Hupeh and Szechwan). The plant possesses a stem growing up $3 \mathrm{~m}$ in height on which can be found violent flowers in April-May. In August, the natural ripe fruits are eaten by human and birds. The fruits and stem of A. quinata have been used as Chinese folk medicines ${ }^{1)}$. The dried fruits, AKEBIAE FRUCTUS (known as 'yochishi' in Japanese) has been long used to an antiphlogistic, a diuretic and an antidote. On the other hand, the dried stem, AKEBIAE CAULIS (known as 'mokutsu' in Japanese) is also used as a diuretic and an antiphlogistic.

In previous reports, various triterpenoid saponins have been isolated and detected in the plant ${ }^{2-8)}$. As newly saponins, the eleven akebosides were isolated by Fujita et $a l .{ }^{2,3}$. Choi $e t a l$. also reported the antinociceptive and anti-inflammatory properties of the stem could be attributed to the sapogenins oleanolic acid and hederagenin ${ }^{7}$. However there is no report of volatile components in this plant. In this report, the components of essential oil from
AKEBIAE FRUCTUS and AKEBIAE CAULIS, the dried fruits and stems of A. quinata, were investigated using GC and GC/MS.

\section{EXPERIMENTAL}

\subsection{Material plant}

Commercially available air-dried fruits and stems of $A$. quinata (AKEBIAE FRUCTUS and AKEBIAE CAULIS from Tokushima, Japan), were obtained from Takasago Yakugyou Co., Ltd. Osaka.

\subsection{Isolation of the essential oil}

The essential oils were obtained by steam distillation for $2 \mathrm{~h}$ with a Likens-Nickerson-type apparatus using diethyl ether, and the oils were dried over anhydrous sodium sulphate prior to analyses.

\subsection{Gas chromatography (GC)}

GC was carried out using a Hewlett Packard 6890 equipped with a flame ionization detector (FID) on a capillary column, DB-5 $(30 \mathrm{~m} \times 0.25 \mathrm{~mm}$, film thickness 0.25 $\mu \mathrm{m})$. The column temperature was programmed from $60-$ $240{ }^{\circ} \mathrm{C}$ at a rate of $4{ }^{\circ} \mathrm{C} / \mathrm{min}$ and held at $240{ }^{\circ} \mathrm{C}$ for $5 \mathrm{~min}$.

* Correspondence to: Mitsuo Miyazawa, Department of Applied Chemistry, Faculty of Science and Engineering, Kinki University, 3-4-1, Kowakae, Higashiosaka-shi, Osaka 577-8502, JAPAN

E-mail: miyazawa@apch.kindai.ac.jp

Accepted October 6, 2006 (received for review September 19, 2006)

Journal of Oleo Science ISSN 1345-8957 print / ISSN 1347-3352 online

http://jos.jstage.jst.go.jp/en/ 
The injector and detector temperature were $240{ }^{\circ} \mathrm{C}$ and $280{ }^{\circ} \mathrm{C}$, respectively. The flow rate of the carrier gas (He) was $0.679 \mathrm{~mL} / \mathrm{min}$.

\subsection{Gas chromatography/mass spectrometry (GC/MS)}

The GC/MS analysis was carried out using a Hewlett Packard model 6890 GC with a Hewlett Packard 5973A MS. The capillary column was a capillary column HP-5MS (30 $\mathrm{m} \times 0.25 \mathrm{~mm}$, film thickness $0.25 \mu \mathrm{m})$. The oven temperature was programmed from $40-240{ }^{\circ} \mathrm{C}$ at a rate of $4{ }^{\circ} \mathrm{C} / \mathrm{min}$ and held at $240{ }^{\circ} \mathrm{C}$ for $5 \mathrm{~min}$. The flow rate of the carrier gas $(\mathrm{He})$ was $1.8 \mathrm{~mL} / \mathrm{min}$. The injector and the detector temperature were $270{ }^{\circ} \mathrm{C}$ and $280{ }^{\circ} \mathrm{C}$, respectively, with the actual temperature in the MS source reaching approximately $230{ }^{\circ} \mathrm{C}$ and the ionization voltage of $70 \mathrm{eV}$.

\subsection{Identification of constituents}

The components of the oil were identified by direct comparison of their mass spectral patterns and retention indices (RI) with our previous reports ${ }^{9-11)}$ and those published in the literature ${ }^{12)}$.

\section{RESULT AND DISCUSSION}

The yields of essential oils obtained by steam distillation from the dried fruits and stems of A. quinata were $0.034 \%$ and $0.016 \%(\mathrm{w} / \mathrm{w})$, respectively. The characteristic odor of fruits oil was powerful spicy and sour with earthry odor. The stems oil gave off a very pungent green odor with faint sweet odor. The oils were analyzed using GC and GC/MS, of which the total ion chromatograms (TIC) were shown in Fig. 1. The chromatograms of fruits oil and stems oil showed presence of 93 and 103 volatile compounds, respectively. The percentage compositions of the oils were listed in Table 1. The fruits oil was revealed the presence of 86 components, representing $98.4 \%$ of the total oil. The major compounds of the fruits oil were limonene (35.5\%), eugenol (14.3\%), octanal (4.4\%) and $p$-cymene (2.9\%). The monoterpenoids, aromatic compounds and saturated short-chain aldehyde $(\mathrm{C} 6 \sim \mathrm{C} 10)$ were main volatile fractions of the fruits oil. It was presumed that powerful spicy odor of eugenol contributes to the characteristic odor of fruits oil. On the other hands, 90 components accounting for $90.5 \%$ of constituents of the stems oil were identified, and the major
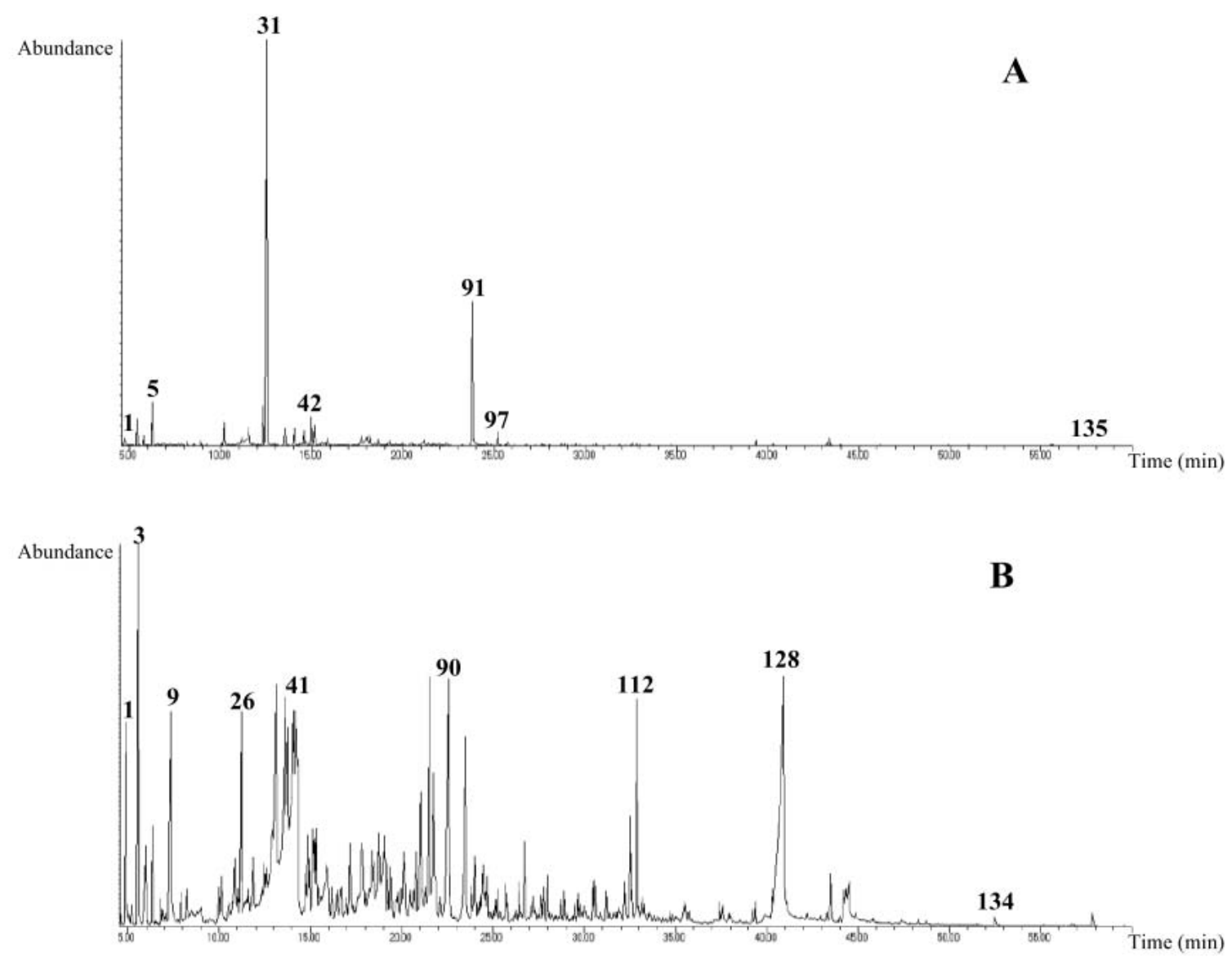

Fig. 1 The Total Ion Chromatograms (TIC) of Essential Oil from the Dried Fruits and Stems of Akebia quinata. A: fruits oil; B: stems oil 
Table 1 The Compositions of Essential Oils from the Dried Fruits and Stems of Akebia quinata.

\begin{tabular}{|c|c|c|c|c|c|c|c|c|c|}
\hline \multirow{2}{*}{ No } & \multirow{2}{*}{ RI } & \multirow{2}{*}{ compound } & \multicolumn{2}{|c|}{ peak area $(\%)$} & \multirow{2}{*}{ No } & \multirow{2}{*}{ RI } & \multirow{2}{*}{ compound } & \multicolumn{2}{|c|}{ peak area $(\%)$} \\
\hline & & & fruits & stems & & & & fruits & stems \\
\hline 1 & 801 & pentanol & 0.5 & 1.7 & 70 & 1217 & decanoic acid & & 1.2 \\
\hline 2 & 808 & (2Z)-pentenol & & 0.1 & 71 & 1219 & $(2 E, 4 E)$-nonadienal & & 0.8 \\
\hline 3 & 821 & hexanal & 1.4 & 2.9 & 72 & 1224 & 4-methylene isophorone & & 0.5 \\
\hline 4 & 832 & ethyl acetate & 0.7 & 0.9 & 73 & 1225 & methyl pelargonate & 1.0 & \\
\hline 5 & 845 & furfural & 2.6 & 0.7 & 74 & 1228 & trans-carveol & & 0.6 \\
\hline 6 & 854 & pentanoic acid & 0.3 & & 75 & 1234 & nerol & 0.4 & \\
\hline 7 & 862 & (2E)-hexenal & & 0.1 & 76 & 1240 & cis-carveol & & 0.5 \\
\hline 8 & 863 & furfryl alcohol & 0.6 & & 77 & 1242 & cumin aldehyde & 0.1 & 0.5 \\
\hline 9 & 875 & hexanol & 0.5 & 3.1 & 78 & 1246 & carvone & 0.3 & 1.1 \\
\hline 10 & 892 & 2-heptenone & $\operatorname{tr}$ & 0.3 & 79 & 1259 & $\gamma$-octalactone & 0.7 & \\
\hline 11 & 902 & heptanal & 0.3 & 0.2 & 80 & 1260 & $p$-anis aldehyde & & 0.4 \\
\hline 12 & 911 & 2-acetyl furan & $\operatorname{tr}$ & & 81 & 1266 & $(2 E)$-decenal & & 0.4 \\
\hline 13 & 914 & pentyl acetate & 0.2 & & 82 & 1276 & (E)-cinnamaldehyde +2 -hexyl thiophene & & 1.4 \\
\hline 14 & 924 & methyl caproate & 0.4 & & 83 & 1280 & pelargonic acid & 1.4 & \\
\hline 15 & 933 & $\alpha$-pinene & 0.2 & & 84 & 1288 & $(E)$-anethole & 0.3 & 2.7 \\
\hline 16 & 954 & (2E)-heptenal & $\operatorname{tr}$ & 0.3 & 85 & 1297 & indole & 0.4 & \\
\hline 17 & 958 & benzaldehyde & $\operatorname{tr}$ & 0.4 & 86 & 1298 & 2-undecanone $+(2 E, 4 Z)$-decadienal & & 2.4 \\
\hline 18 & 961 & 5-methyl furfural & 1.8 & & 87 & 1305 & carveol & 0.4 & \\
\hline 19 & 968 & heptanol & 0.4 & 0.3 & 88 & 1309 & carvacrol & & 0.2 \\
\hline 20 & 975 & $\beta$-pinene & 0.3 & & 89 & 1317 & 4-vinyl-o-guaiacol & 0.2 & \\
\hline 21 & 977 & 2-propyl thiophene & & 0.2 & 90 & 1323 & $(2 E, 4 E)$-decadienal & 0.2 & 3.7 \\
\hline 22 & 980 & 1-octen-3-ol & & 0.6 & 91 & 1362 & eugenol & 14.3 & 0.4 \\
\hline 23 & 983 & 3-octanone & & 0.3 & 92 & 1368 & $\gamma$-nonalactone & & 0.8 \\
\hline 24 & 986 & 6-methyl-5-hepten-2-one & & 0.2 & 93 & 1380 & $\alpha$-copaene & 0.1 & \\
\hline 25 & 989 & myrcene & 0.7 & & 94 & 1387 & lauric acid & & 0.5 \\
\hline 26 & 991 & 2-pentylfuran & 0.9 & 1.7 & 95 & 1387 & $(E)$ - $\beta$-damascenone & 0.4 & 0.3 \\
\hline 27 & 1000 & octanal & 4.4 & 0.2 & 96 & 1395 & $\beta$-elemene & 0.2 & \\
\hline 28 & 1010 & $(2 E, 4 E)$-heptadienal & & 0.6 & 97 & 1406 & methyl eugenol & 1.1 & \\
\hline 29 & 1015 & $\alpha$-terpinene & 0.3 & & 98 & 1407 & 2-dodecanone + methyl eugenol & & 0.3 \\
\hline 30 & 1023 & $p$-cymene & 2.9 & 0.1 & 99 & 1424 & $\beta$-caryophyllene & 0.4 & \\
\hline 31 & 1029 & limonene & 35.5 & 0.3 & 100 & 1446 & paeonol & & 0.2 \\
\hline 32 & 1031 & $(3 Z, 5 Z)$-octadien-2-one $+1,8$-cineole & & 0.2 & 101 & 1456 & geranyl acetone & & 0.6 \\
\hline 33 & 1037 & lavendor lactone & 0.4 & 0.4 & 102 & 1458 & $\alpha$-humulene & $\operatorname{tr}$ & \\
\hline 34 & 1043 & benzeneacetaldehyde & 0.3 & 1.4 & 103 & 1472 & $\gamma$-decalactone & & 0.2 \\
\hline 35 & 1053 & $\gamma$-hexalactone & $\operatorname{tr}$ & & 104 & 1486 & ar-curcumene & 0.1 & 0.2 \\
\hline
\end{tabular}




\section{J. Kawata, M. Kameda and M. Miyazawa}

\begin{tabular}{|c|c|c|c|c|c|c|c|c|c|}
\hline \multirow{2}{*}{ No } & \multirow{2}{*}{ RI } & \multirow{2}{*}{ compound } & \multicolumn{2}{|c|}{ peak area $(\%)$} & \multirow{2}{*}{ No } & \multirow{2}{*}{ RI } & \multirow{2}{*}{ compound } & \multicolumn{2}{|c|}{ peak area $(\%)$} \\
\hline & & & fruits & stems & & & & fruits & stems \\
\hline 36 & 1058 & $\gamma$-terpinene & 1.4 & & 105 & 1489 & $(E)$-b-ionone & $\operatorname{tr}$ & 0.3 \\
\hline 37 & 1061 & $(2 E)$-octenal & & 1.0 & 106 & 1491 & $\beta$-selinene & 0.2 & \\
\hline 38 & 1065 & vinyl caproate & & 0.8 & 107 & 1498 & 2-tridecanone & & 0.4 \\
\hline 39 & 1073 & trans-linalool oxide & 1.5 & 0.1 & 108 & 1500 & $\alpha$-selinene & 0.1 & \\
\hline 40 & 1074 & $(3 E, 5 Z)$-octadien-2-one & & 0.1 & 109 & 1522 & $\delta$-cadinene & 0.1 & \\
\hline 41 & 1081 & hexanoic acid & & 22.7 & 110 & 1549 & $\alpha$-calacorene & & 0.2 \\
\hline 42 & 1089 & cis-linalool oxide & 2.3 & 0.5 & 111 & 1556 & elemol & & 0.2 \\
\hline 43 & 1098 & $(3 E, 5 E)$-octadien-2-one & & 0.9 & 112 & 1583 & ar-turmerol & $\operatorname{tr}$ & 2.2 \\
\hline 44 & 1101 & linalool & 2.0 & 1.0 & 113 & 1589 & caryophyllene oxide & 0.2 & \\
\hline 45 & 1105 & nonanal & 1.8 & 0.6 & 114 & 1616 & humulene epoxide II & $\operatorname{tr}$ & \\
\hline 46 & 1113 & $(2 E, 4 E)$-octadienal & & 0.3 & 115 & 1635 & 1-epi-cubenol & 0.2 & \\
\hline 47 & 1117 & phenylethylalcohol & 0.8 & & 116 & 1647 & hinesol & & 0.4 \\
\hline 48 & 1122 & trans-p-mentha-2,8-dien-1-ol & 0.3 & & 117 & 1648 & epi- $\alpha$-muurolol & 0.1 & \\
\hline 49 & 1126 & methyl caplylate & 0.6 & & 118 & 1659 & $\beta$-eudesmol & & 0.9 \\
\hline 50 & 1127 & heptanoic acid & & 2.0 & 119 & 1661 & neointermederol & 0.3 & \\
\hline 51 & 1132 & limona ketone & 0.1 & & 120 & 1662 & $\alpha$-cadinol & & 0.2 \\
\hline 52 & 1137 & cis-p-mentha-2,8-dien-1-ol & $\operatorname{tr}$ & & 121 & 1669 & ar-turmerone & 0.2 & 0.3 \\
\hline 53 & 1143 & $(3 E)$-nonen-2-one & & 0.4 & 122 & 1678 & (3Z)-butylidene phthalide & 0.1 & \\
\hline 54 & 1147 & camphor & 0.1 & & 123 & 1682 & cadalene & & 0.2 \\
\hline 55 & 1150 & (E)-5-ethyl-6-methyl-3-hepten-2-one & & 0.6 & 124 & 1740 & (Z)-ligustilide & $\operatorname{tr}$ & \\
\hline 56 & 1153 & lilac aldehyde & 0.2 & & 125 & 1771 & myrstic acid & & 0.2 \\
\hline 57 & 1158 & menthone & & 0.3 & 126 & 1847 & 6,10,14-trimethyl pentadecan-2-one & $\operatorname{tr}$ & 0.1 \\
\hline 58 & 1160 & $(2 E)$-nonenal & 0.1 & 0.7 & 127 & 1927 & methyl palmitate & 0.4 & 0.2 \\
\hline 59 & 1172 & cis-linalyl oxide & 0.1 & & 128 & 1966 & palmitic acid & 0.2 & 8.0 \\
\hline 60 & 1177 & borneol +2 -pentyl thiophene & & 0.4 & 129 & 2096 & methyl linoleate & 0.2 & \\
\hline 61 & 1179 & terpinen-4-ol & 1.3 & & 130 & 2102 & methyl oleate & 0.6 & \\
\hline 62 & 1182 & menthol & & 2.0 & 131 & 2108 & methyl phytol & & 0.4 \\
\hline 63 & 1188 & octanoic acid & 2.3 & & 132 & 2128 & methyl stearate & $\operatorname{tr}$ & \\
\hline 64 & 1193 & $\alpha$-terpineol & 1.2 & 0.7 & 133 & 2140 & ethyl phytol & & 0.3 \\
\hline 65 & 1194 & $p$-cymen-8-ol & & 0.6 & 134 & 2152 & linoleic acid & & 0.7 \\
\hline 66 & 1198 & methyl salicylate & & 0.9 & 135 & 2700 & heptacosane & 0.2 & \\
\hline 67 & 1200 & dodecane & 0.3 & & & & & & \\
\hline 68 & 1206 & decanal & 0.6 & 1.4 & & & & & \\
\hline 69 & 1212 & octyl acetate & 0.1 & & & & total & 98.4 & 90.5 \\
\hline
\end{tabular}

RI: Retention Index on a DB-5 column; peak area (\%) was related to total detected compounds by GC; $\operatorname{tr}$ : trace $<0.1$. 
compounds of the oil were hexanoic acid (22.7\%), palmitic acid (8.0\%), (2E, $4 E)$-decadienal (3.7\%), and hexanol (3.1\%). The stems oil had high content of saturated fatty acids (C6 $\sim \mathrm{C} 16)$, and unsaturated short-chain aldehyde $(\mathrm{C} 6 \sim \mathrm{C} 10)$. The pungent green odor of the unsaturated short-chain aldehyde, such as $(2 E)$-hexenal, seemed to play an important role in the characteristic aroma of stems oil. Hexanal and linalool were detected as common main compounds (peak area $>1.0 \%$ ) to two oils, however there was hardly a similarity between fruits oil and stems oil.

To the best of our knowledge, the essential oil of Lardizabalaceae has not been the subject of previous studies. Thus this study is the first report on the volatile composition of this family.

\section{ACKNOWLEDGMENT}

This work was supported by "High-Tech Research Center" project for Private Universities: matching fund subsidy from MEXT (Ministry of Education, Culture, Sports, Science and Technology), 2004-2008.

\section{References}

1. Namba, T. Coloured illustrations of wakan-yaku, Hoikusya Publishing Co., Ltd. (1980).

2. Fujita, M.; Itokawa, H.; Kumekawa, Y. Constituents of clematis and Akebia Subspecies. II. Saponins isolated from the stem of Akebia quinata 1, Yakugaku Zasshi. 94, 194-198 (1974).

3. Kumekawa, Y.; Itokawa, H.; Fujita, M. Constituents of clematis and Akebia Species. III. Structures of akebo- sides isolated from the stem of Akebia quinata, Chem. Pharm. Bull. 22, 2294-2300 (1974).

4. Higuvhi, R.; Kawasaki, T. Pericarp saponins of Akebia quinata Decne. II. Arjunolic and norarjunolic acids, and their glycosides, Chem. Pharm. Bull. 24, 13141323 (1976).

5. Higuchi, R.; Komori, T.; Kawasaki, T. Mass spectra of triterpene saponin permethylate of the oleanane type, Chem. Pharm. Bull. 24, 2610-2618 (1976).

6. Akira, I.; Itokawa, H. 30-Noroleanane saponins from callus tissues of Akebia quinata, Phytochemistry. 28, 2663-2665 (1989).

7. Choi, J.; Jung, H.J.; Lee, K.T.; Park, H.J. Antinociceptive and anti-inflammatory effects of the saponin and sapogenins obtained from the stem of Akebia quinata, J. Med. Food. 8, 78-85 (2005).

8. Jiang, D.; Gao, Q.P.; Shi, S.P.; Tu, P.F. Triterpenoid saponins from the fruits of Akebiae quinata, Chem. Pharm. Bull. 54, 595-597 (2006).

9. Miyazawa, M.; Kawata, J. Identification of the key aroma compounds in dried roots of Rubia cordifolia, J. Oleo Sci. 55, 37-39 (2006).

10. Utsunomiya, H.; Kawata, J.; Chanoki, W.; Shirakawa, N.; Miyazawa, M. Components of essential oil from woods of Prunus mume Sieb. et Zucc. J. Oleo Sci. 54, 609-612 (2005).

11. Miyazawa, M.; Fujita, T.; Yamafuji, C.; Matsui, M.; Kasahara, N.; Takagi, Y.; Ishikawa, Y. Chemical composition of volatile oil from the roots of Periploca sepium. J. Oleo Sci. 53, 511-513 (2004).

12. Adams, R.P. Identification of essential oil components by gas chromatography/quadrupole mass spectroscopy, Academic Press, New York (2001). 